\title{
Modelling the performance of a corroded pipe section repaired with three-parts epoxy grout and with three-parts epoxy grout plus nanofiller
}

\author{
Siti Norasyikin Hj Kariya ${ }^{1}$ and Pang Jen Lim ${ }^{2, *}$ \\ ${ }^{1,2}$ Civil Engineering Programme, Universiti Teknologi Brunei, Jln Tungku Link, Gadong, BE1410, Brunei
}

\begin{abstract}
Steel pipelines have been used for the transportation of oil and gas for more than a century. With exposure to the harsh condition of the environment, steel pipelines are subjected to corrosion that deteriorates their function through metal loss. To remedy this, several repair techniques have been developed to extend their service life, particularly, techniques that do not interrupt the flow of the oil and gas. There are three main components in a Fibre-reinforced Polymer (FRP) composite repair which are (1) FRP composite wrap, (2) infill material, and (3) interlayer adhesive. Past research had looked at enhancing the infill material, which is usually an epoxy grout, with the aim to reduce or remove the number of FRP composite wrap layers. One of the ways to enhance the infill material is to add Graphene Nanoplatelets (GNPs) to the epoxy grout. This was proven by carrying out different mechanical tests on a neat three-part epoxy (Infill A) and a three-part epoxy with $0.1 \%$ GNPs added by weight (Infill B). With the mechanical properties obtained for both infill materials, the pipe sections were then modelled with a finite element software to determine the repair performance without the use of FRP composite wrap. The difference of failure pressures between the pipe repaired using Infill A and Infill B over the unrepaired pipe were $2.7 \%$ and $4.2 \%$ respectively. The failure of the repair was due to the debonding of the infill materials from the pipe section. However, this research has provided significant information in understanding the properties of the infill materials as well as the numerical modelling on a repaired pipe section.
\end{abstract}

\section{Introduction}

The use of steel pipelines is one of the most efficient, reliable and cost-efficient network system for transporting natural resources such as oil and gas over long distances. However, these pipelines are continuously exposed during their service to damage due to factors such as corrosion, third-party damage, construction defects and forces by natural movements [1-4]. External corrosion is the main reason for most pipeline failures. This deterioration reduces the pipeline's strength and eventually reduces its structural integrity and lifespan. Furthermore, the failure could lead to leakage and explosion causing significant negative impacts such as financial and asset loss, loss of life and severe environmental damage [4,5]. Pipeline repair technology plays an important role in extending the service life of the pipelines, preventing accidents and maintaining the safety of the operation.

There are a number of rehabilitation techniques that are widely used for both onshore and offshore deteriorated pipelines. The traditional repair solution was to remove the entire pipe or only the localised damage section and then replace it with a new one. This technique normally stops the pipeline's operation.
Another repair technique involves covering the damaged section with a full-encirclement steel sleeve or using a steel clamp. These repairs use external steel sleeves either welded or bolted to the external surface of the pipelines. However, this technique involves bulky equipment, high costs and is time-consuming especially for underground pipelines $[1,2,4,6-8]$. In addition, this method is most suited for a straight pipe section and is more difficult for joints or bends.

Recent studies show the acceptance of using FibreReinforced Polymer (FRP) composites as an alternative repair technique for the rehabilitation of oil and gas pipelines $[3,7,9]$. The two current repair techniques are the flexible wet lay-up system and the pre-cured layered system. These systems are applicable to more situations, have good resistance to corrosion, do not interrupt the flow through the pipe and do not require any hot work [7,10-12]. Generally, there are three components of these systems as shown in Fig. 1. They are (1) the high strength FRP composite wraps, (2) the interlayer adhesive and (3) the high compressive infill material. The adhesive acts as a bonding agent to hold the pipe and the composite laminates together creating a cohesive structural unit. The infill material, usually an epoxy grout, is used to fill the surface defects and acts as a

\footnotetext{
${ }^{*}$ Corresponding author: pangjen.lim@utb.edu.bn
} 
smooth bed for load transfer from the pipe to the composite wrap. This repair technique is considered to be the most suitable option for rehabilitating metallic structures and there is ongoing research on improving the infill material $[3,13,10]$.

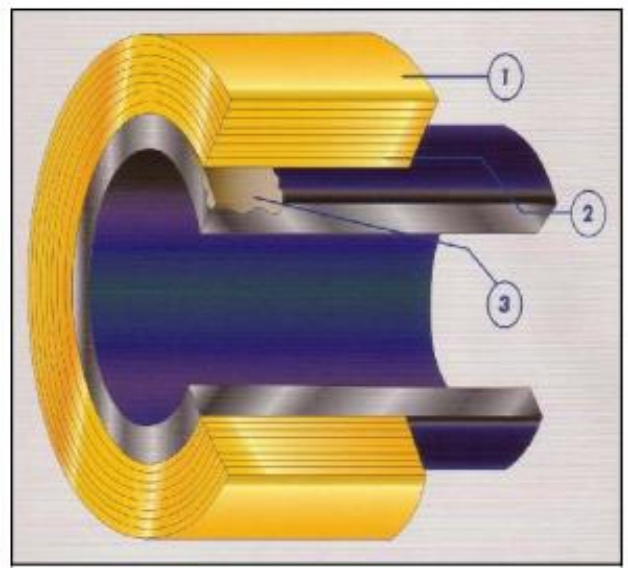

Fig. 1. Three main components of composite repair: (1) FRP composite, (2) interlayer adhesive and (3) infill material [14]

Graphene, an allotrope of carbon, was discovered in 2004. The carbon atoms of graphene are arranged in flat layers of hexagonal rings that are continuous. Research by Lee et. al. [15] concluded that a single layer of Graphene has an elastic modulus of $1 \mathrm{TPa}$ and a tensile strength of $130 \mathrm{GPa}$. It also has a high strength-to-weight ratio. Graphene nano-platlets (GNPs) are nano-size graphene made up of discontinuous hexagonal rings, and they have similar properties to graphene itself. They are suitable for addition to the epoxy (the infill material), via either the epoxy resin or the epoxy hardener to alter the epoxy's properties [16,17] and the product is hereby called the nanofiller.

Though increasing the amount of GNP would increase the strength of the nanofiller, it is not costeffective to use large quantities of it $[4,5,10]$. Research by $[16,17]$ have also shown that manually mixing GNPs into epoxy is not very effective in improving the strength characteristics of the epoxy as the particles of the graphene powder used are usually clumped-up initially. A proper method of dispersion is required to break up the clumped-up graphene powder and two such methods are the Ultra-sonication method and the Three Roll Mill method. The previous research [16-18] have also determined that it is not cost effective to use both methods together.

The aim of this study is to determine, with finite element modelling, the performance of corroded pipe sections repaired with (1) three-parts epoxy grout (Infill A) and with (2) three-parts epoxy grouts plus nanofiller (Infill B), and to determine if the modelling is sufficiently accurate. However, material tests were required first to determine the properties of the two types of grout and if the three roll mill method of dispersion will produce a grout with better performance.

\section{Literature Review}

A series of similar experiments were conducted at Universiti Teknologi Malaysia by Azraai et. al. [5] and
Lim [4] to study how the addition of GNPs to epoxy grouts would improve the latter's properties. Azraai et. al. [5] conducted comparative compressive, tensile and flexural tests on samples of commercially available neat epoxy grout versus epoxy grout with $2.0 \mathrm{wt} \%$ of GNPs, dispersed in the epoxy hardener using only a high-speed hand mixer and without the ultra-sonication or the three roll mill methods. The epoxy grout was consisted of epoxy resin, hardener and fine silica in the ratio of $2: 1: 12$ by weight as recommended by the manufacturer. The GNPs were in powder form and their average particle thickness and diameter were reported to be 0.68 $-3.41 \mathrm{~nm}$ and $1-4 \mathrm{~nm}$ respectively [19]. The tests were performed in accordance to ASTM: D695, D638 and D790 respectively [20-22]. The grout with the GNPs showed a $1 \%$ increase in compressive strength, a 5\% decrease in flexural strength and a 19\% decrease in tensile strength over the neat grout, perhaps indicating that merely mixing the GNPs into the resin or hardener would not modify the grout by much.

Lim [4] did similar comparative tests on the same type of three-part epoxy grout and added a lap shear test following ASTM: D1002 [23] to study the adhesion of the infill material when applied on steel surfaces. His control is the neat epoxy grout, whereas two other specimens, G-0.2 and G-0.8, had 0.2 and $0.8 \mathrm{wt} \%$ respectively, of GNPs added. For the latter two specimens, the GNPs were first weighed and then dispersed in an acetone solution using an ultrasound sonicator for one hour. The solution was next allowed to cool at room temperature (30 degrees $\mathrm{C}$ ), the acetone allowed to evaporate, and the dispersed GNPs were left behind. The details of the mixing procedure of the three parts with the GNPs is the same as the procedure that will be used in the new study of this paper, and this can be found in the methodology section.

Lim [4] found that the compressive strength decreased by $36 \%$ and $17 \%$ from that of the neat sample for the G-0.2 and G-0.8 samples, respectively, the tensile strength decreased by $27 \%$ and $0 \%$ respectively from that of the neat sample, the flexural strength increased by $5 \%$ and $8 \%$ respectively from that of the neat sample, and the lap shear strength increased by $137 \%$ and $124 \%$ respectively from that of the neat sample. Overall, using a small amount of GNP would actually worsen the compressive and tensile strengths, but these strengths improve with increases in the amount of GNP used. The lap shear strengths also increased by more than one fold in both cases.

Lim [4] had also carried out experimental work on the repair of a corroded pipeline using the same infill material, by performing a hydrostatic burst test. Fig. 2 shows the specimen used. It has a $100 \times 100 \mathrm{~mm}$, section where the steel has been reduced to a thickness of 3.55 $\mathrm{mm}$, half of the original thickness. However, all sharp edges have been rounded before the burst test. The specimen satisfies the requirements of the ASME-PCC-2 standard [24]. Four specimens were tested. They were (1) an undamaged pipe, (2) a corroded pipe, (3) a corroded pipe repaired with composite wrap and neat infill material, and (4) a corroded pipe repaired with composite wrap and modified infill material. The burst 
pressures were $39 \mathrm{MPa}, 26.8 \mathrm{MPa}, 33 \mathrm{MPa}, 33.9 \mathrm{MPa}$ respectively. He next followed the experimental tests with finite-element analyses of the specimens and he was able to get failure pressures that were similar to those of the experiments.
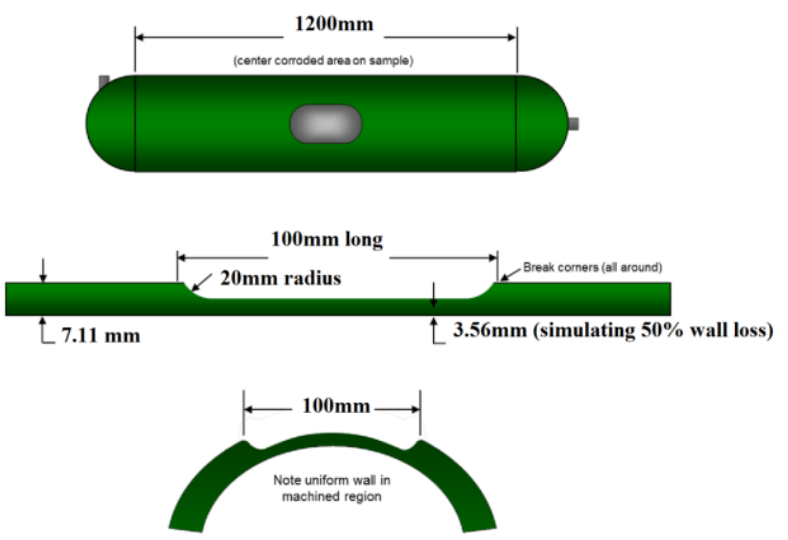

Fig. 2. Simulated corroded pipe specimen [4]

\section{Methodology}

For the material test part of this study, the three-parts epoxy grout (Infill A) and the three-parts epoxy grout with nanofiller (Infill B) were first produced. Infill A is made with resin and hardener from a commercially available brand and was made by following the manufacturer's guidelines of mixing the resin with the hardener with an electric mixer, at low speeds, until consistent. Next, the fine silica was added followed by more mixing until a homogeneous grout was obtained. The ratio by weight for the resin:hardener:fine silica mix is $2: 1: 12$.

For Infill B, the GNP had an average thickness and particle diameter of the GNPs was $0.68-3.41 \mathrm{~nm}$ and 1 $-4 \mathrm{~nm}$, respectively [19]. It was first weighed and then dispersed by the Three Roll Mill method using a Three Roll Mill Unit such as the one show in this reference [25]. The dispersed GNPs were then mixed with hardener using an electric mixer, at low speeds, until consistent. Then the resin was next added with more mixing for two minutes and followed by adding the fine silica and mixing until a homogeneous grout was obtained. The ratio by weight for the resin:hardener:fine silica: GNP mix is 2:1:12:0.1.

Five specimens each, for compressive, tensile, flexure and laps shear tests, were prepared according to ASTM: D695, D638, D790 and D1002 respectively. Some extra specimens produced due to some obviously wrong results. The specimens were allowed to cure for up to 28 days. The specimens were finally tested in an Instron 5567 Universal Testing Machine. A summary of the average results are shown in Table 1.

Table 1. Material properties of Infill A and B

\begin{tabular}{|c|c|c|}
\hline Strength & Infill A (Control) & $\begin{array}{c}\text { Infill B } \\
\text { (w/ nanofiller) }\end{array}$ \\
\hline \hline Compressive $(\mathrm{MPa})$ & 100.24 & 107.36 \\
\hline Tensile $(\mathrm{MPa})$ & 18.17 & 21.2 \\
\hline Fleural $(\mathrm{MPa})$ & 33.5 & 34.14 \\
\hline
\end{tabular}

\begin{tabular}{|l|l|l|}
\hline Lap Shear $(\mathrm{MPa})$ & 2.57 & 4.12 \\
\hline
\end{tabular}

Next, finite element modelling (FEM) was conducted on (1) an undamaged pipe section, and (2) the same pipe with a corroded section (modelled) as a damaged pipe). The pipe burst pressure of these models were then compared with experimental pipe burst pressures data of the same specimens previously performed by [4]. Upon validation of the modelling technique, the models were then modified to study the behaviour of (3) the same pipe with the damaged section repaired with three-part epoxy grout (Infill A), and (4) the same pipe with the damaged section repaired with three-part epoxy grout and nanofiller (Infill B).

Table 2 presents the summary of the steps and data used to model the four specimens in ABAQUS ${ }^{\circledR}$ v6.121 , a commercially available finite element software. Fig. 3 shows the FE model of the pipe section.

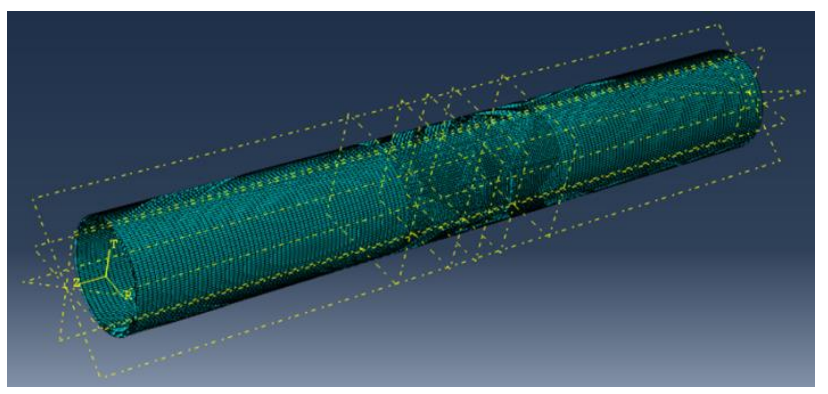

Fig. 3. FE Model of pipe section

The first modelling technique validation on the undamaged pipe section was made against the experimental test and the same FEM of the same specimen, both performed by [4]. The results are shown in Table 3. The burst pressure of the current FEM was $+13.3 \%$ larger than the experimental value, while that from [4] was $+7.3 \%$ larger. While the discrepancy for the current model is not small, it was decided to carry on and consider the modelling of the damaged pipe section.

The second validation on the damaged pipe section was made against the experimental test and the same FEM of the same specimen, both performed by [4]. The results are shown in Table 4. The burst pressure of the current FEM was $+2.2 \%$ larger than the experimental value, while that from [4] was $+7.4 \%$ larger. The discrepancy for the current model is smaller than that performed by [4], indicating that the modelling technique of the current study is good. Overall, it was decided to consider the modelling technique in this study as acceptable.

With that, the same modelling technique was used for further analyses of the repaired damaged pipe section using Infill A and Infill B. The result of the experimental test was extracted and tabulated in the result section of this paper.

Table 2. Finite element modelling steps and data

1. Geometric development of individual parts 


\begin{tabular}{|c|c|}
\hline $\begin{array}{l}\text { Pipe section } \\
\text { Length: } 1200 \mathrm{~mm} \\
\text { Outer diameter: } 168.3 \mathrm{~mm} \\
\text { Thickness: } 7.11 \mathrm{~mm}\end{array}$ & $\begin{array}{l}\frac{\text { Infill Material }}{\text { Circumferential length: } 100} \\
\text { mm } \\
\text { Circumferential width: } 100 \\
\text { mm }\end{array}$ \\
\hline \multicolumn{2}{|l|}{ 2. Assign material properties } \\
\hline $\begin{array}{c}\text { Steel pipe } \\
\text { Density: } 7850 \mathrm{~kg} / \mathrm{m}^{3} \\
\text { Young's modulus: } 222 \mathrm{GPa} \\
\text { Poisson ratio: } 0.3 \\
\text { True ultimate tensile } \\
\text { strength: } 557 \mathrm{MPa}\end{array}$ & $\begin{array}{l}\frac{\text { Infill material (Infill A) }}{\text { Ultimate compressive }} \\
\text { strength: } 100.24 \mathrm{MPa} \\
\text { Poisson ratio: } 0.35 \\
\text { Ultimate tensile strength: } 18.2 \\
\text { MPa } \\
\text { Infill material (Infill B) } \\
\text { Ultimate compressive } \\
\text { strength: } 107.36 \mathrm{MPa} \\
\text { Poisson ratio: } 0.35 \\
\text { Ultimate tensile strength: } 21.2 \\
\mathrm{MPa}\end{array}$ \\
\hline \multicolumn{2}{|c|}{ 3. Assemble the parts and assigning bonding properties } \\
\hline \multicolumn{2}{|c|}{$\begin{array}{l}\text { - To make sure that the parts are in a correct position for } \\
\text { further analysis. } \\
\text { Bonding properties: surface-to-surface contact }\end{array}$} \\
\hline \multicolumn{2}{|c|}{ 4. Loading and boundary condition } \\
\hline $\begin{array}{l}\text { Applied loading (on pipe's } \\
\text { internal surface): } 0.1 \mathrm{MPa} / \mathrm{s} \\
\text { Running time: } \\
500 \mathrm{~s}\end{array}$ & $\begin{array}{l}\text { Boundary condition: } \\
\text { Fixed ended }\end{array}$ \\
\hline \multicolumn{2}{|l|}{ 5. Meshing of parts } \\
\hline \multicolumn{2}{|c|}{ Mesh size: $7.11 \mathrm{~mm}$} \\
\hline \multicolumn{2}{|l|}{ 6. Model analysis } \\
\hline $\begin{array}{l}\text { Plotted graph of internal pres } \\
\text { and determines its failure pre }\end{array}$ & $\begin{array}{l}\text { against circumferential strain } \\
\text { re at the pipe's ultimate tensile } \\
\text { gth }\end{array}$ \\
\hline
\end{tabular}

Table 3. Summary table comparing the burst pressure of undamaged pipe section

\begin{tabular}{|l|l|l|l|l|}
\hline & $\begin{array}{l}\text { Theoretical } \\
\text { analysis }\end{array}$ & $\begin{array}{l}\text { Exptl. test } \\
\text { by [4] }\end{array}$ & $\begin{array}{l}\text { FEM } \\
\text { by [4] }\end{array}$ & $\begin{array}{l}\text { Current } \\
\text { FEM }\end{array}$ \\
\hline \hline $\begin{array}{l}\text { Burst } \\
\text { pressure } \\
\text { (MPa) }\end{array}$ & 40.56 & 39 & 41.86 & 44.2 \\
\hline $\begin{array}{l}\text { \% diff. } \\
\text { with } \\
\text { exptl. }\end{array}$ & - & - & $+7.3 \%$ & $+13.3 \%$ \\
\hline
\end{tabular}

Table 4. Summary table comparing the burst pressure of damaged pipe section

\begin{tabular}{|l|l|l|l|}
\hline & $\begin{array}{l}\text { Exptl. test } \\
\text { by [4] }\end{array}$ & $\begin{array}{l}\text { FEM by } \\
{[4]}\end{array}$ & $\begin{array}{l}\text { Current } \\
\text { FEM }\end{array}$ \\
\hline \hline $\begin{array}{l}\text { Burst pressure } \\
(\mathrm{MPa})\end{array}$ & 26.8 & 28.78 & 27.39 \\
\hline \% diff. with exptl. & - & $+7.4 \%$ & $+2.2 \%$ \\
\hline
\end{tabular}

\section{Results and Discussion}

The infill materials used for repairing the damaged pipe section were Infill A (neat epoxy grout) and were compared to the same damaged pipe section repaired with Infill B (epoxy grout with $0.1 \mathrm{wt} \%$ GNPs content). Table 5 shows tabulated data of the burst pressures for all analysed models. From the analysed FEMs, both repaired pipes have a lower burst pressure compared with the undamaged pipe model with $28.12 \mathrm{MPa}$ for pipe repaired with Infill $\mathrm{A}$ and $28.52 \mathrm{MPa}$ for pipe repaired with Infill B. There is a slight increase in the burst pressure of $2.7 \%$ and $4.2 \%$ for pipe repaired with Infill A and Infill $\mathrm{B}$, respectively. The internal pressure vs circumferential strain behaviour of the analyses can be seen in Fig. 4, showing similar performance was obtained between the two repaired models.

Table 5. Tabulated pressure failure of the models

\begin{tabular}{|c|c|}
\hline Models & Burst pressure (MPa) \\
\hline \hline Undamaged pipe & 44.2 \\
\hline Damaged pipe & 27.38 \\
\hline Pipe repaired with infill A & 28.12 \\
\hline Pipe repaired with infill B & 28.52 \\
\hline
\end{tabular}

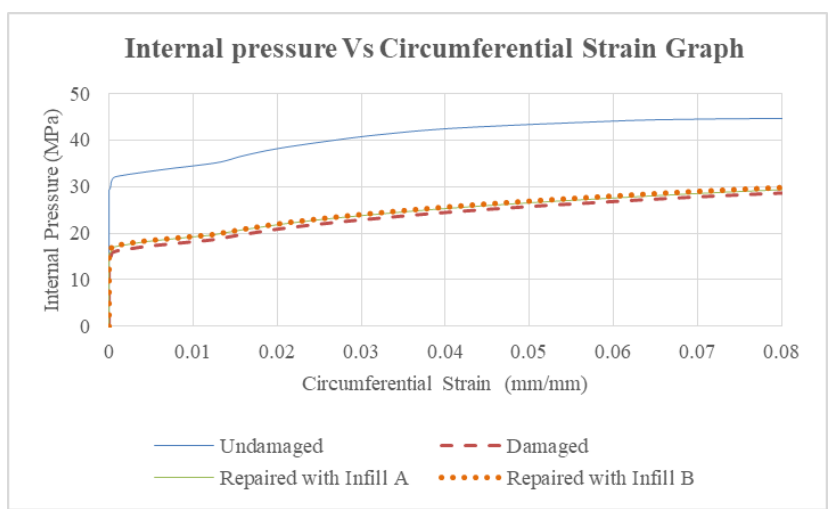

Fig. 4. Internal pressure against circumferential strain graph

\section{Conclusion and Recommendations}

This research has successfully executed the objectives which are modelling the behaviour of undamaged, damaged and repaired pipe section subjected to the same loading condition. The repaired pipe with Infill A and Infill B shows an increase of $2.7 \%$ and $4.2 \%$ in burst pressure respectively comparing to the damaged pipe section. In terms of the competence of the repair, both analyses prove to be an ineffective repair due to the insignificant increase in the pressure failure. However, Infill $B$ has the potential of enhancing the recent rehabilitation techniques which might able to reduce the number of FRP composite. This can form the basis of future research in this area.

\section{References}

1. D. A. Jones, Principles and Prevention of Corrosion, 2nd Edition, 2nd ed. Pearson, 1995.

2. AEA Technology Consulting,

"Temporary/permanent pipe repair Guidelines," Abingdon, UK, 2001.

3. J. M. Duell, J. M. Wilson, and M. R. Kessler, "Analysis of a carbon composite overwrap pipeline repair system," Int. J. Press. Vessel. Pip., vol. 85, no. 11, pp. 782-788, 2008.

4. K. S. Lim, "Behaviour of repaired composite steel pipeline using epoxy grout as infill material," Universiti Teknologi Malaysia, 2016.

5. S. N. . Azraai, K. S. Lim, N.Yahaya, and N. M. Noor, "Infill materials of epoxy grout for pipeline rehabilitation and repair," Malaysian J. 
Civ. Eng., vol. 27, no. 1, pp. 162-167, 2015.

6. J. Kou and W. Yang, "Application Progress of Oil and Gas Pipeline Rehabilitation

Technology," in International Conference on Pipelines and Trenchless Technology, 2011.

7. M. Shamsuddoha, M. M. Islam, T. Aravinthan, A. Manalo, and K. Lau, "Effectiveness of using fibre-reinforced polymer composites for underwater steel pipeline repairs," Compos. Struct., vol. 100, pp. 40-54, 2013.

8. T. D. Williamson, Steel Repair Sleeves. T.D. Williamson, 2016.

9. Z. Zhang et al., "Mechanical and anticorrosive properties of graphene/epoxy resin composites coating prepared by in-situ method," Int. J. Mol. Sci., vol. 16, 2015.

10. M. Shamsuddoha, M. M. Islam, T. Aravinthan, A. Manalo, K. Lau, and D. Elder, "Fibre Composites for High Pressure Pipeline Repairs, in-air and subsea - An Overview," in 3rd Asiapacific Conference on FRP in Structures (APFIS 2012), 2012.

11. H. S. Da Costa Mattos, J. M. L. Reis, L. M. Paim, M. L. Da Silva, F. C. Amorim, and V. A. Perrut, "Analysis of a glass fibre reinforced polyurethane composite repair system for corroded pipelines at elevated temperatures," Compos. Struct., vol. 114, pp. 117-123, 2014.

12. J. A. Peck, G. Li, S. S. Pang, and M. A. Stubblefield, "Light intensity effect on UV cured FRP coupled composite pipe joints," Compos. Struct., vol. 64, no. 3-4, pp. 539-546, 2004.

13. D. Schnerch, M. Dawood, S. Rizkalla, and E. Sumner, "Proposed design guidelines for strengthening of steel bridges with FRP materials," Constr. Build. Mater., vol. 21, no. 5, pp. 1001-1010, May 2007.

14. Savcor Products Australia, "Clock Spring Pipeline Repair," 2018.

15. C. Lee, X. Wei, J. W. Kysar, and J. Hone, "Measurement of the Elastic Properties and Intrinsic Strength of Monolayer Graphene," Science (80-. )., vol. 321 , no. 5887, pp. 385-388, 2008.

16. J. Wei, T. Vo, and F. Inam, "Epoxy/graphene nanocomposites - processing and properties: a review," $R S C A d v$., vol. 5, pp. 73510-73524, 2015.

17. R. Atif, I. Shyha, and F. Inam, "Mechanical, thermal, and electrical properties of grapheneepoxy nanocomposites-A review," Polymers (Basel)., vol. 8, no. 8, 2016.

18. J. Wei, R. Atif, T. Vo, and F. Inam, Graphene Nanoplatelets in Epoxy System: Dispersion, Reaggregation, and Mechanical Properties of Nanocomposites, vol. 2015. 2015.

19. Ugent Tech Sdn Bhd, "Graphene Nanoplatelets UG Pro 680 technical data sheet." 2014.

20. ASTM D695-10, "Standard Test Method for Compressive Properties of Rigid Plastics." ASTM International, West Conshohocken, PA, 2010.
21. ASTM D638-10, "Standard Test Method for Tensile Properties of Plastics." ASTM International, West Conshohocken, PA, 2010.

22. ASTM D790-10, "Standard Test Methods for Flexural Properties of Unreinforced and Reinforced Plastics and Electrical Insulating Materials." ASTM International, West Conshohocken, PA, 2010.

23. ASTM D1002-10, "Standard Test Method for Apparent Shear Strength of Single-Lap-Joint Adhesively Bonded Metal Specimens by Tension Loading (Metal-to-Metal).” ASTM International, West Conshohocken, PA, 2010.

24. ASME International, "ASME PCC-2-2001 Repair of Pressure Equipment and Piping." The American Society of Mechancial Engineers, New York, USA, 2011.

25. Exakt, "EXAKT Superfine Series Three Roll Mill Units," 2018. [Online]. Available: https://exaktusa.com/dispersionequipment/superfine-models/. 